\title{
Local Dynamics and Structure of Solvated Proton in Water
}

\author{
Song Hi Lee \\ Department of Chemistry, Kutugsung Lniversity, Pusan 608-736, Korea. E-mail: shlee aks.ackr \\ Received November 17, 2008, Accepted December 24, 2008
}

Key Wonds: Molecular dỵnamics simulation. OSS2 potential. Solvated proton. Grotthus chain mechanism

It is well known that anomalously high ionic mobility of $\mathrm{H}^{-}$ compared to other ions ${ }^{3}$ is owing to the transfer of $\mathrm{H}^{+}$by the Grotthus chain mechanism that does not involves its actual motion through the solution. Instead of a single. highly solvated proton moving through the solution, it is believed that there is an effective motion of a proton which involves the rearrangement of bonds through a long chain of water molecules. A closer insight into the transport of $\mathrm{OH}^{-}$reveals that the large value of the limiting molar conductance of $\mathrm{OH}^{-}$is also related to the Grotthus chain mechanism in addition to its actual motion through the solution

A hydrogen ion in a dilute aqueous solution exists as a range of structures from the Eigen cation ${ }^{-\cdot 4} \mathrm{H}_{9} \mathrm{O}_{4}^{+}$. consisting of a hỵdronium ion $\mathrm{H}_{3} \mathrm{O}^{-}$hydrogen bonded to three water molecules. to the Zundel cation ${ }^{56} \mathrm{H}_{3} \mathrm{O}_{2}{ }^{-}$in which the excess proton is shared between two water molecules. Details of the mechanism of transport of the $\mathrm{H}^{+}$ion are broadly understood from first principles simulations of the excess proton in small systems of 32 water molecules ${ }^{-9}$ and from Extended Valence Bond (EVB) theory calculations of larger sy stems ${ }^{1(1,1]}$ but the structural details around the hydrogen ion are in dispute. Marx et al ${ }^{5}$ found that $\mathrm{H}^{+}$ion transport in aqueous solutions is driven by solvent fluctuations in the second solvation shell of the Eigen complex as suggested earlier by Agmon ${ }^{8.9}$ with proton transfer(PT) occurring via a Zundel intermediate. However. Asthagiri et $a l^{1 / 2}$ reported that $a b$ initio molecular dynamics simulations and quasi-chemical theory, with two different electron density finctionals. suggest a preponderance of Zundel-like structures. but a symmetrical ideal Zundel cation is not observed.

Several attempts at developing dissociable water potentials in classical simulations to study proton hydration and $\mathrm{H}^{+} / \mathrm{OH}^{-}$ neutralization reactions in small clusters have been made previously beginuing with pioneering work on central force models by Stillinger. Lemberg. David and Weber. ${ }^{13.17}$ Recently. Ojamäe. Shavitt and Singer ${ }^{18}$ designed a family of potentials for solvated proton $\mathrm{H}^{+}\left(\mathrm{H}_{2} \mathrm{O}\right)_{n}$ complexes in water called the OSSn potentials where $\mathrm{n}=1$ to 3 are fitted to $a b$ initio M Plesset (MP2) calculations. Despite the electronic structure $a b$ initio calculations by quantum chemical methods of these potentials, time propagation by classical simulation methods may result in inevitable miss-leading in the motion of light proton

In the present note, we report the result of molecular dy namics(MD) simulation for the transport of $\mathrm{H}^{+}$ion in bulk water using this dissociating water model ${ }^{18}$ derived from $a b$ initio calculations at the level of MP2. Although more accurate results could possibly be obtained with the OSS3 potential. the OS\$2 model also gives good results judging by simulations of neat water except exhibiting too large bond angles for water molecules. When that deficiency is not a serious problem, it is our preferred choice because of faster and less elaborate computer code implementation compared to the OSS3 model which contains three body dipole coupling terms.

\section{Molecular Models and MD Simulation Methods}

The OS\$2 model ${ }^{18}$ is a polarizable model in which the induced dipole moment $\mu$ at each oxygen atom site $i$ is obtained self consistently from

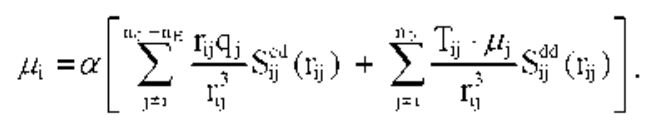

by imposing the conditions $d r^{\prime} d r_{k l}=0\left(k=1,2 \ldots, n_{\phi}\right)$, where $I_{e l}$ is the electrostatic energy. $n_{-}$and $n_{H}$ are the numbers of oxygen and hydrogen atoms. $\alpha$ is the polarizability of the atom and $S_{i j}^{i d}\left(r_{i j}\right)$ and $S_{i j}^{d d}\left(r_{i j}\right)$ are the cutoff functions for the charge-dipole and dipole-dipole interactions respectively. Ewald summations were used in our simulations with the parameter for $\kappa=5.0 / \mathrm{L}$ and the real-space cut distance $r_{\text {cut }}$ and $K_{\text {max }}$ chosen as $0.5 \mathrm{~L}$ and 7 , respectively. where $\mathrm{L}$ is the length of the box. ( $\sim 9.87 \AA$ for 32 water molecules) The double summations in reciprocal space. which camot be reduced to a single summation due to the cutoff functions. were ignored. This is reasonable as the distances in reciprocal space are larger than the length $L$ of the box. The equations of motion were solved using Gear's fifth order predictor-corrector algorithm ${ }^{19}$ with a time step of $2 \times 10^{-16}$ second $(0.2 \mathrm{fs})$. The simulations were first validated by checking our results against Ojamäe's work for pure water using the same OSS2 model. The calculated oxygen-hydrogen $(\mathrm{O}-\mathrm{H})$ radial distribution function and the hydration number $\mathrm{n}(\mathrm{r})$ for hydrogen in the 216 molecule pure water system are nearly identical. even though Ojantäe et al. used a different method for the Ewald summations in the calculation of the induced dipole moment.

\section{Results and Discussion}

In our MD simulations of a protonated water in 31 water molecules the $\mathrm{H}_{3} \mathrm{O}^{+}$ion exists as the Eigen cation $\mathrm{H}_{2} \mathrm{O}^{-}\left(\mathrm{H}_{2} \mathrm{O}\right)_{2}$ (Fig. I (a)) before proton transfer (PT) occurs. This complex is solvated by water molecules which form a second solvation shell. Thermal fluctuations break the $\mathrm{H}$-bond of a water 


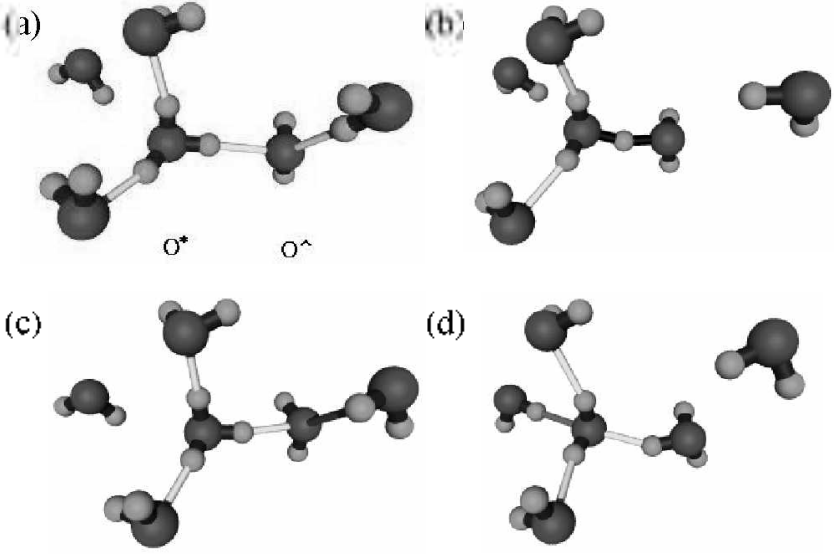

Figure 1. Representative configurations showing the mechanism of proton transfer leading to the transport of a hydrogen ion in a simulation of one $\mathrm{H}_{2} \mathrm{O}$ ion in 31 water molecules using the OSS2 potential. (a) $\mathrm{H}_{3} \mathrm{O}$ ion stabilized as an Eigen complex $\mathrm{H}_{3} \mathrm{O}\left(\mathrm{H}_{2} \mathrm{O}\right)_{3}$ showing three coordination of $\mathrm{H}_{3} \mathrm{O}$ and a water molecule in the second solvation shell. (b) Loss of water in the second solvation shell in (a) and the formation of the Zundel intermediate $\mathrm{H}_{5} \mathrm{O}_{2}$. (c) Return to (a) from the Zundel intermediate in the absence of proton transfer. (d) Completion of proton transfer via the Zundel intermediate to form a new $\mathrm{H}_{3} \mathrm{O}^{-}$ion.

molecule in the second solvation shell of $\mathrm{H}_{3} \mathrm{O}^{+}$. leaving the three coordinated $\mathrm{H}_{3} \mathrm{O}^{-}$with shorter hy'drogen bonded $\mathrm{O}-\mathrm{O}$ distances. To explain the mechanism of PT, the oxygen in the three coordinated $\mathrm{H}_{3} \mathrm{O}^{+}$is characterized as $\mathrm{O}^{*}$. The hydrogen atom linking the shortest $\mathrm{O}^{*}$-O distance in a hydrogen bond is the most likely one to undergo PT by moving closer to the oxygen of the solvating water molecule. designated as $\mathrm{O}^{\wedge}$. to form the Zundel intermediate $\left[\mathrm{H}_{2} \mathrm{O}^{-} \cdots \mathrm{H}^{\cdots} \cdots \mathrm{O}^{\wedge} \mathrm{H}_{ \pm}\right]^{+}$. Two water molecules are chosen as being hy'drogen bonded only if their interoxygen distance is less than $3.5 \mathrm{~A}$, and simultaneously the $\mathrm{O}-\mathrm{H} \cdots \mathrm{O}$ angle is less than $30^{\circ}{ }^{\circ}$ ' This most active $\mathrm{H}$ fluctuates between two $\mathrm{O}^{\prime} \mathrm{s}$ (Fig. l(b)). If the $\mathrm{O}^{\wedge}$ returns to its former state by forming a hydrogen bond with an extraneous water molecule (a H-bond shown as thin dark in Fig. I(c)), the most active $\mathrm{H}$ atom goes back to $\mathrm{O}^{*}$ and PT does not occur. Alternatively. if the $\mathrm{O}^{*}$ atom of the original Eigen complex. now present in the Zundel form, becomes four coordinated by forming a $\mathrm{H}$-bond with a fourth water molecule (a $\mathrm{H}$-bond shown as thin dark in Fig. $\mathrm{I}(\mathrm{d})$ ). the most active $\mathrm{H}$ within the Zundel complex moves to $\mathrm{O}^{\wedge}$ and PT occurs to form a new $\mathrm{H}_{3} \mathrm{O}^{+}$ion that is stabilized in the next step by the formation of an Eigen complex (not shown). The initial existence of a water near the old $\mathrm{H}_{3} \mathrm{O}^{-}$is essential for $\mathrm{PT}$ to occur since the newly formed H-bond (thin dark in Fig. I(d)) stabilizes the conversion of the old $\left(\mathrm{H}_{3} \mathrm{O}^{*}\right)^{-}$to form a new four coordinated water molecule after PT has occurred.

The preexistence of a water molecule near the Eigen complex $\mathrm{H}_{3} \mathrm{O}^{+}\left(\mathrm{H}_{2} \mathrm{O}\right)_{3}$ is necessary for PT to occur to an adjacent water molecule via the $Z$ undel intermediate. Our simulation of $\mathrm{H}^{-}$ ion transport using the dissociating OSS2 model is validated by their close agreement with the result of first principles AIMD simulations of the same systems containing 32 water molecules.

We select two sets of configurations for which the displacement coordinate $\hat{\delta}=\left|\mathrm{R}_{\mathrm{C}^{\circ} \times \mathrm{H}}-\mathrm{R}_{(\cdot \mathrm{H})}\right|$ is small $(\hat{o}<0.1)$ and large $(\hat{o}$
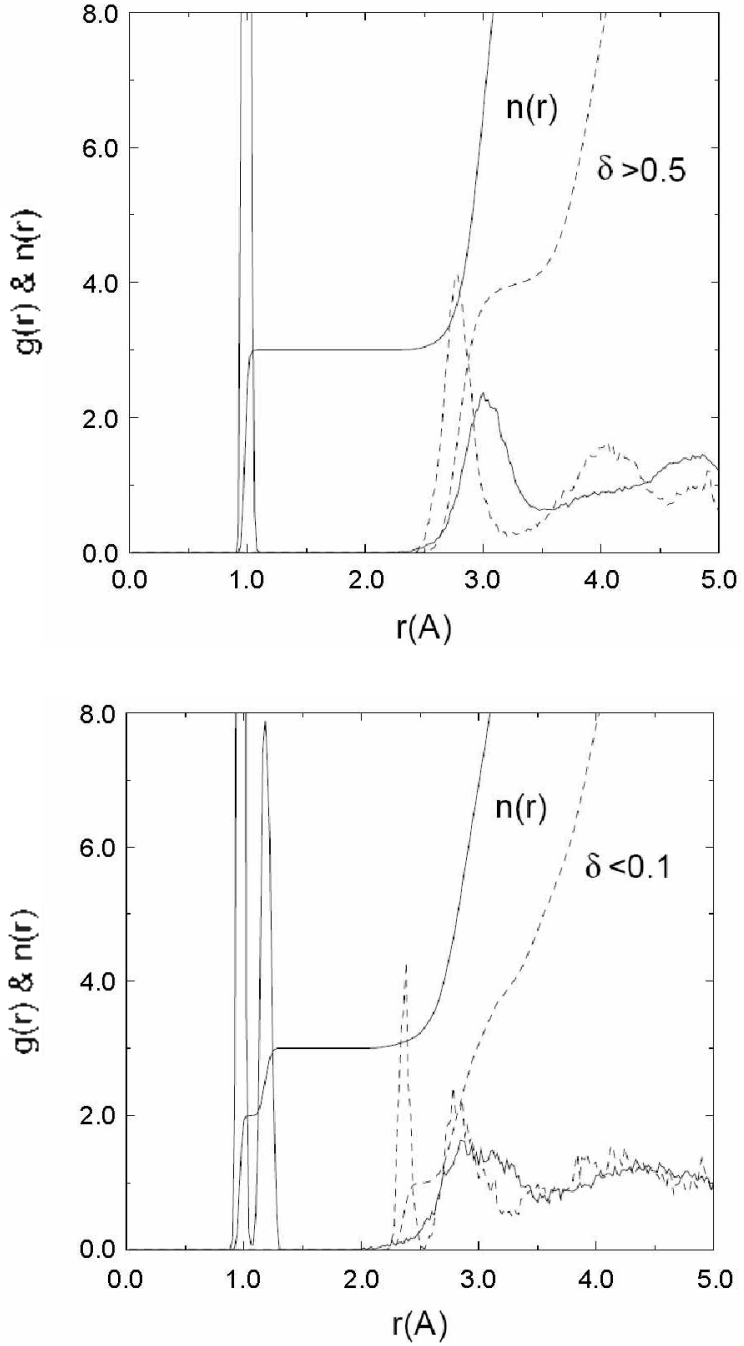

Figure 2. The radial distribution functions $\mathrm{g}_{0 * \mathrm{H}}$ (solid line) and $\mathrm{g}_{0} *_{0}$ (dotted line) and the corresponding coordination numbers $\mathrm{Il}_{\mathrm{C}}{ }^{\circ \mathrm{H}}$ (solid line) and no-o (dotted line) with respect to the oxygen atom $\mathrm{O}^{*}$ of the protonated water $\left(\mathrm{H}_{3} \mathrm{O}^{*}\right)^{-}$in 31 water molecules for configuration in which the displacement coordinate (a) $\delta>0.5$ betore or after proton transfer (Eigen complex) and (b) $\delta<0.1$ (Zundel intemediate

$>0.5$ ) before or after PT. Here $\mathrm{R}_{{ }_{-H}}$ and $\mathrm{R}_{\overline{\mathrm{CH}}}$ are the respective distances of the shared proton from $\mathrm{O}^{*}$ and $\mathrm{O}$. the oxygen of a water molecule to which $\mathrm{O}^{*}$ is hydrogen bonded. A small $\delta$ indicates a potential pathway for PT (panel (b) of Fig. 1) and a large value of ò suggests the opposite (panels (a) and (d) of Fig. 1).

Fig. 2 shows the radial distribution functions $\mathrm{g}_{\mathrm{O}}{ }^{\times} \mathrm{H}$ and $\mathrm{g} \times \mathrm{O}$ and the corresponding coordination numbers $\mathrm{n}_{\mathrm{C}-\mathrm{H}}$ and $\mathrm{n}_{\mathrm{C}} \cdot \mathrm{G}$ with respect to the oxygen atom $\mathrm{O}^{*}$ of the protonated water $\mathrm{H}_{3} \mathrm{O}^{*-}$ in 31 water molecules for configuration in which the displacement coordinate (a) $\delta>0.5$ and (b) $\hat{o}<0.1$. Fig. 2(a) shows that for large $o$ the oxygen $\mathrm{O}^{*}$ of the hydronium ion accepts on average three hydrogen bonds in complete agreement with the presence of an $\mathrm{H}_{3} \mathrm{O}^{+}$ion and consistent with presence in the Eigen complex confinmed by visual observations (panel (a) in Fig. 1). However, integration up to the first minimum at $3.20 \AA$ bevond the broad peak of the $\mathrm{O}^{*}$-O distribution function at $2.78 \dot{A}$ corresponds to a coordination number $n_{\cdots} \cdot$ of 4 
which is one more than expected from the Eigen complex. This probably signifies the presence of a non-bonded water molecule near $\mathrm{H}_{3} \mathrm{O}^{+}$which as we observed earlier is necessary for proton transfer to occur. A coordination number, $n:{ }^{*} \mathrm{C}$ of three follows from integration from zero to $2.88 \AA$ which lies beyond the peak at $2.78 \mathrm{~A}$ and consistent with the visually observed Eigen structure. For the displacement coordinate $\delta<$ 0.1 (Fig. 2(b)) the peak in the $\mathrm{O}^{*}-\mathrm{O}$ pair correlation function $\mathrm{g}_{0 . \times} \times$ at $2.78 \mathrm{~A}$ for $\delta>0.5$ is split into a sharp peak at $2.38 \mathrm{~A}$ and a broader envelope with two prominent peaks at $2.78 \AA$ and $2.86 \mathrm{~A}$ respectively. The runuing coordination number shows a plateau at $1 n_{1}=1$ corresponding to the peak at $2.38 \AA$ which is the oxygen-oxygen distance in the Zundel intermediate. This number becomes 4 through 3 continually which indicates the presence of a non-bonded water molecule near $\mathrm{H}_{3} \mathrm{O}^{+}$as seen in Fig. 2(a). The peak in the $\mathrm{O}^{*}-\mathrm{H}$ pair correlation function $g_{I^{-} \cdot \mathrm{H}}$ at $0.99 \AA$ for $\delta>0.5$ is also split into peaks two at $0.98 \AA$ and $1.17 \mathrm{~A}$ respectively with overall coordination number of 2 and 3 respectively consistent with the presence of two chemical bonds and one hydrogen bond associated with the $\mathrm{O}^{*}$ atom of the Zundel intermediate (see panel (b) of Fig. 1).

In summary. classical simulations using the OSS2 model potential derived from $a b$ initio calculations can be used to understand the mechanism of PT in bulk water. This may enable the study of larger and more complex acid-base systems by the same methods when first principles simulations are not feasible. For hydrogen ion the starting point is the Eigen complex and PT proceeds through a Zundel intermediate. This conclusion in the transport mechanism of hydrogen ion in bulk water is inbroad agreement with first principles AMD simulations of $\mathrm{H}^{-}$ions by Tuckerman et al. MD simulation for a larger system of $\mathrm{H}^{+}$in 216 water molecules and investiga- tion for dynamic property such as ionic mobility of $\mathrm{H}^{-}$and $\mathrm{OH}^{-}$ions are in progress.

\section{References}

1. Koneshan, S.: Rasaiah, J. C; Lynden-Bell, R. M.; Lee, S. H. J. Plws. Chem. B 1998, 102, 4193.

2. Wicke, E.; Eigen, M.; Ackermann, Th. Z. Phusik Chem (N. F.) 1954, 1.340.

3. Eigen, M.: Kruse, W.: Maass, G.: DeMayer, L. Prog React. Kin. 1964.2 .285

4. Eigen. M. Angew. Chem. Int Edn. Engl. 1964, 3, 1 .

5. Zundel, G.; Metzger, H. Z. Physik Chem (N. F.) 1968, 58,225

6. Zundel, G. The Hudrogen Bond in Recent Developments in Theory and Experinents. II Structure and Spectroscopy Schuster. P.: Zundel, G.; Sandorfy, C., Eds.; North-Holland: Amsterdam, 1976.

7. Marx, D; Tuckemann, M. E.; Parrinelleo, M. Nature 1999, 397,601 .

8. Agmon, N. Chent Phws Lett 1985, 24t, 456

9. Agmon, N.: Gutman, M. Isr. J. Chem 1999, 39, III-IV

10. Vuillemmier. R.: Borgis. D. J. Chem. Phus 1999. 111.4251.

11. Schmitt, U. W.: Voth, G. A. J. Chem. Phus 1999, 111, 9361

12. Asthagiri, D; Pratt, L. R.: Kress, I. D. Proc Narl Acad Sci. L.S.1. 2005, 102,6704 .

13. Lemberg, H. L.; Stillinger, F. H. J. Chem Phns. 1975, 62, 1677.

14. Stillinger, F. H.: David, C. W. J. Chem. Phys $1978,69,1473 ; J$. Chem. Phys. 1980, 73, 3384.

15. Stillinger, F. H.; Weber, T. A. Chem. Phys. Lent 1981, 79, 259.

16. Stillinger, F. H. Weber, T. A. J. Chem. Phws. 1982, 76, 4028.

17. Weber, T. A.; Stillinger, F. H. J. Phys. Chent 1982, 86, 1314 .J. Chem. Phys 1982, 77, 4150 .

18. Ojamäe, L.; Shavitt, I.: Singer, S. I. J. Chem Phys 1998, 109, $5 \$ 47$.

19. Gear. W. C. Numencal Initial Valte Problems in Ordinan Differential Equations; Prentice-Hall: Englewood Cliffs, NJ, 1971.

20. Soper. A. K. Phillips, M. G. Chem Phs 1986, 107, 47; Teixeira, JT Bellisent-Funel, M. C.; Chen, S. H. J. Plys. Condens. Matter 1990, 2, SA 105 